\title{
Critérios para o teste de tetrazólio na estimativa do potencial germinativo em macaúba
}

\author{
Leonardo Monteiro Ribeiro(1), Queila Souza Garcia(2), Denise Maria Trombert Oliveira(2) \\ e Silma Conceição Neves ${ }^{(1)}$
}

\begin{abstract}
(1)Universidade Estadual de Montes Claros, Departamento de Biologia Geral, Campus Prof. Darcy Ribeiro, Vila Mauricéia, CEP $39401-089$ Montes Claros, MG. E-mail: leomrib@hotmail.com, silma_neves@yahoo.com.br (2)Universidade Federal de Minas Gerais, Instituto de Ciências Biológicas, Departamento de Botânica, Avenida Antonio Carlos, n 6.627, Pampulha, Caixa Postal 486, CEP 31270-901 Belo Horizonte, MG. E-mail: queilagarcia@gmail.com,dmtoliveira@icb.ufmg.br
\end{abstract}

Resumo - O objetivo deste trabalho foi estabelecer critérios para a aplicação do teste de tetrazólio em embriões de macaúba (Acrocomia aculeata). Para a elaboração do esquema de avaliação, foram realizadas avaliações anatômicas, identificação de padrões de coloração por solução de 2,3,5-trifenil cloreto de tetrazólio a 0,5\% por quatro horas e cultivo in vitro de embriões. Em um experimento, foram avaliados três períodos de précondicionamento das sementes por imersão em água, por 12 e 24 horas, associados a duas temperaturas de coloração, 35 e $40^{\circ} \mathrm{C}$, em dois lotes de sementes além do controle sem pré-condicionamento. Em outro experimento, foram testadas em três lotes de sementes, três concentrações da solução de tetrazólio $(0,5,0,75$ e $1 \%$ ), associadas a dois tempos de coloração (duas e quatro horas). Utilizou-se o cultivo in vitro de embriões para comparação dos resultados. Um esquema de avaliação com dez padrões de coloração, associados a três classes de vigor, foi definido com base na anatomia dos embriões e no desenvolvimento de plântulas in vitro. $\mathrm{O}$ tratamento de pré-condicionamento em água não é necessário, e se deve aplicar o tempo de coloração de quatro horas, em solução de sal de tetrazólio, a $0,5 \%$ e $35^{\circ} \mathrm{C}$.

Termos para indexação: Acrocomia aculeata, 2,3,5-trifenil cloreto de tetrazólio, cultivo in vitro de embriões.

\section{Criteria for tetrazolium tests in the estimationof the germination potential of macaw palm}

\begin{abstract}
The objective of this study was to establish criteria for the tetrazolium test in embryos of macaw palm (Acrocomia aculeata). To develop the evaluation scheme, anatomical analyses were performed, and staining patterns were identified using a $0.5 \%$ 2,3,5-triphenyl tetrazolium chloride solution for four hours, and embryo was cultured in vitro. In one experiment, three prior seed-soaking times in water (for 12 and 24 hours, besides a control without seed pre-conditioning), associated with two color temperatures $\left(35\right.$ and $\left.40^{\circ} \mathrm{C}\right)$ in two seed lots were evaluated. In another experiment, three concentrations of tetrazolium solution $(0.5,0.75$ and $1 \%$ ), associated with two staining times (two and four hours), were tested in three seed lots. In vitro embryo culture was used to compare the results. An evaluation scheme, with ten staining patterns associated with three classes of vigor, was defined, based on the anatomy of the embryo and on the in vitro seedling development. Pre-soaking is not necessary, and staining for four hours in a solution of tetrazolium salt, at $0.5 \%$ and $35^{\circ} \mathrm{C}$, should be used.
\end{abstract}

Index terms: Acrocomia aculeata, 2,3,5-triphenyl tetrazolium chloride, in vitro embryo culture.

\section{Introdução}

A palmeira macaúba [Acrocomia aculeata (Jacq.) Lodd. ex. Mart.] é apontada como uma das principais alternativas, entre as oleaginosas brasileiras, para a produção de biocombustíveis, por sua produtividade e resistência à seca (Hiane et al., 2005; Teixeira, 2005; Bandeira, 2008). Porém, a implantação de cultivos comerciais é dificultada pela pronunciada dormência das sementes (Teixeira, 2005; Bandeira, 2008) que, pelo elevado teor de óleo (Hiane et al., 2005), são também susceptíveis à deterioração (Bewley \& Black, 1994; Marcos Filho, 2005). Estudos sobre métodos de avaliação da qualidade da semente de macaúba podem contribuir para o avanço do conhecimento necessário à domesticação da espécie. 
O teste de tetrazólio é um dos principais métodos de avaliação da qualidade de sementes (Brasil, 1992; Association of Official Seed Analysts, 2002; Marcos Filho, 2005) e tem sido amplamente utilizado em razão de sua rapidez, precisão, baixo custo e possibilidade de estimativa do vigor (França Neto et al., 2000; Marcos Filho, 2005). O método baseia-se na diferenciação entre tecidos vivos e mortos, pela coloração avermelhada do trifenilformazan formado em tecidos vivos, em consequência da redução do sal 2,3,5-trifenil cloreto de tetrazólio, pela atividade de enzimas desidrogenases (Lakon, 1949; Brasil, 1992; França Neto et al., 2000).

O teste de tetrazólio é especialmente útil na estimativa da viabilidade de sementes que apresentam dormência ou germinação lenta (França Neto et al., 2000; Wood et al., 2005). Neste caso, são necessários testes prévios, que relacionem o padrão de coloração ao potencial de germinação (Wood et al., 2005). Spera et al. (2001) utilizaram a germinação in vitro de embriões, como meio de avaliar a eficiência e estabelecer o padrão de coloração para o teste de tetrazólio para o buriti (Mauritia flexuosa L.). Essa estratégia pode ser utilizada para a macaúba, uma vez que Bandeira (2008) verificou que embriões da espécie germinam com facilidade, quando cultivados in vitro, a despeito da dormência das sementes.

Para a adequação da metodologia do teste de tetrazólio para novas espécies, além da definição da concentração da solução, do tempo de exposição e da temperatura (Brasil, 1992; França Neto et al., 2000; Bhering et al., 2005), outros aspectos devem ser considerados. Como o principal objetivo do teste é verificar a condição fisiológica de estruturas essenciais à germinação (Lakon, 1949), o conhecimento da anatomia do embrião é imprescindível (França Neto et al., 2000; Marcos Filho, 2005). Essa situação é particularmente importante para palmeiras, nas quais o eixo embrionário é interno ao pecíolo cotiledonar e tem posição variável de acordo com a espécie (Orozco-Segovia et al., 2003; Henderson, 2006). Wood et al. (2005) verificaram peculiaridades no padrão de coloração em sementes oleaginosas em que a difusão da solução ou a coloração pode ser dificultada; nesse caso, são necessários padrões de coloração específicos. Hiane et al. (2005) constataram teores de óleo de 52,9\% em sementes de macaúba, o que indica a necessidade da adequação da metodologia para a espécie. Outro aspecto a ser considerado é a avaliação da necessidade de pré-condicionamento por imersão em água, proposto para sementes de várias espécies (Brasil, 1992; Association of Official Seed Analysts, 2002, 2005), e que pode favorecer a ativação enzimática, a difusão da solução e a exposição do embrião (Brasil, 1992; Costa \& Marcos Filho, 1994; Barros et al., 2005; Bhering et al., 2005).

No Brasil, alguns trabalhos têm sido realizados com o teste de tetrazólio em palmeiras (Ferreira \& Sader, 1987; Lin, 1988; Fernandes et al., 2007), embora apenas Spera et al. (2001) tenham reportado o uso de técnicas para avaliar a eficiência do teste. Além disso, das regras oficiais brasileiras (Brasil, 1992), constam somente recomendações para o açaizeiro (Euterpe edulis Mart.).

O objetivo deste trabalho foi estabelecer critérios para a aplicação do teste de tetrazólio em macaúba, por meio da elaboração de um esquema de avaliação de resultados e pela definição de valores para as variáveis da metodologia.

\section{Material e Métodos}

Inicialmente, foram realizadas avaliações anatômicas em embriões de macaúba, para localizar as regiões essenciais à germinação, as quais deverão ser destacadas pelo teste de tetrazólio. Para tanto, após abscisão, foram coletados frutos, em cinco plantas de população natural no Município de Montes Claros, MG, em março de 2009, e as sementes foram retiradas dos frutos. Para a observação em microscópio, dez embriões foram isolados com auxílio de estilete, fixados em FAA 50 (formalina, ácido acético, álcool etílico), desidratados em série etílica e incluídos em parafina, tendo-se usado butanol como solvente (Johansen, 1940). Cinco embriões foram seccionados transversalmente e cinco longitudinalmente, em micrótomo rotativo, com $6 \mu \mathrm{m}$ de espessura. As secções seriadas foram coradas com azul de toluidina a $0,05 \%$, pH 4,7 (O'Brien et al., 1964) e montadas em Permount. As secções foram observadas em microscópio óptico Ken Avision TT-1500 e fotografadas com câmera digital Cannon A-620 acoplada.

Para a identificação dos padrões de coloração dos embriões expostos ao sal de tetrazólio, utilizaram-se três lotes de frutos, provenientes de três populações naturais de macaúba do Município de Montes Claros, com dois, cinco e oito meses de armazenamento. A umidade dos lotes foi determinada pelo método da estufa, com secagem de cinco repetições de dez sementes a $105^{\circ} \mathrm{C}$, por 24 horas (Brasil, 1992), e foi

Pesq. agropec. bras., Brasília, v.45, n.4, p.361-368, abr. 2010 
utilizada para referência aos lotes. As sementes foram retiradas dos frutos, e 50 embriões provenientes de cada lote foram isolados e submetidos à coloração pelo sal de tetrazólio. Com base nas informações para o açaizeiro (Brasil, 1992) e para o coquinho-azedo - Butia capitata (Mart.) Becc. (Fernandes et al., 2007), procedeu-se à imersão de cinco repetições de dez embriões, sem pré-condicionamento, em béquer com capacidade de $20 \mathrm{~mL}$, com $10 \mathrm{~mL}$ de solução de 2,3,5-trifenil cloreto de tetrazólio, a $0,5 \%, \mathrm{com} \mathrm{pH} 7,1$, por quatro horas, na ausência de luz e à temperatura de $35^{\circ} \mathrm{C} \mathrm{em}$ germinador. Após este período, os embriões foram lavados em água destilada e avaliados individualmente em estereomicroscópio com iluminação fluorescente, tendo-se verificado a ocorrência e intensidade da coloração das estruturas do embrião, e tendo-se descrito os padrões observados.

Com a finalidade de associar padrões de coloração dos embriões às classes de vigor, realizou-se o cultivo in vitro de embriões, e as plântulas obtidas foram classificadas conforme o estádio de desenvolvimento. Para isso, 50 embriões de cada lote foram destinados ao cultivo in vitro, a partir de protocolo adaptado de Bandeira (2008). As sementes foram extraídas dos frutos com auxílio de torno manual de bancada, e os embriões foram isolados com auxílio de estilete e dispostos em solução de 100 ppm de ácido ascórbico. Após a desinfestação em solução de cloro, a $0,25 \%$, por 10 min, em condições assépticas, em câmara de fluxo laminar, os embriões foram colocados em tubos de ensaio de $12 \mathrm{x} 1 \mathrm{~cm}$ de dimensões, com $2 \mathrm{~mL}$ do meio previamente autoclavado a $121^{\circ} \mathrm{C}$ por $20 \mathrm{~min}$ : sais MS, em $75 \%$ da concentração original; $0,4 \mathrm{mg} \mathrm{L}^{-1}$ de tiamina; $1 \mathrm{mg} \mathrm{L}^{-1} \mathrm{de}$ piridoxina; $0,5 \mathrm{mg} \mathrm{L}^{-1}$ de ácido nicotínico; $100 \mathrm{mg} \mathrm{L}^{-1} \mathrm{de}$ mioinositol; $0,5 \mathrm{~g} \mathrm{~L}^{-1}$ de caseína hidrolizada; $3 \mathrm{~g} \mathrm{~L}^{-1} \mathrm{de}$ carvão ativado; $30 \mathrm{~g} \mathrm{~L}^{-1}$ de sacarose; $6 \mathrm{~g} \mathrm{~L}^{-1}$ de ágar; com $\mathrm{pH}$ ajustado para 5,7. Os embriões foram mantidos em germinador na ausência de luz, à temperatura de $30^{\circ} \mathrm{C}$. Após 30 dias de cultivo, as plântulas foram retiradas dos tubos, avaliadas visualmente e agrupadas em estádios de desenvolvimento, conforme Henderson (2006).

A partir da determinação de áreas essenciais à germinação, pelas avaliações anatômicas e de informações da literatura (Brasil, 1992; França Neto et al., 2000; Spera et al., 2001; Association of Official Seed Analysts, 2002, 2005), foi proposto um esquema de avaliação pela associação dos padrões de coloração a classes de vigor, estimadas pelos estádios de desenvolvimento das plântulas cultivadas in vitro. Experimentos, descritos a seguir, foram estabelecidos para verificar a adequação do esquema de avaliação e definir valores para as variáveis da metodologia.

Para avaliar o efeito do pré-condicionamento - por imersão das sementes em água - e o da temperatura utilizada durante a coloração, utilizaram-se dois lotes de frutos, provenientes de duas populações naturais de macaúba do Município de Montes Claros, armazenadas por cinco e oito meses. Primeiramente, determinou-se a umidade das sementes (Brasil, 1992), e o teste de tetrazólio foi executado conforme descrito anteriormente, tendo-se avaliado os tratamentos tempo de pré-condicionamento em água em 12 e 24 horas, mais o controle sem prévia imersão, associados a duas temperaturas durante a coloração - 35 e $40^{\circ} \mathrm{C}$. O experimento foi instalado em delineamento inteiramente casualizado, em esquema fatorial com 3 tempos de pré-condicionamento e 2 temperaturas de coloração, com cinco repetições de dez embriões cada. Paralelamente, foi realizada a cultura de embriões, como descrito anteriormente, com cinco repetições de dez embriões provenientes de cada lote.

Para a avaliação do esquema de determinação proposto, calculou-se, em cada repetição, o número de embriões pertencentes a cada classe. Os dados foram convertidos em percentual e transformados em arco seno $(\mathrm{x} / 100)^{0,5}$. Utilizou-se análise de variância, para se verificar o efeito dos tratamentos sobre o percentual de embriões viáveis e vigorosos. Quando constatadas diferenças significativas, pelo teste F, utilizou-se o teste de Tukey a $5 \%$ de probabilidade, para comparação das médias. $\mathrm{Na}$ avaliação da cultura de embriões, em cada repetição, determinou-se o número de plântulas em diferentes estádios de desenvolvimento e, a partir daí, estimou-se o percentual de embriões pertencentes às classes de vigor. Para comparação dos resultados de cada tratamento do teste de tetrazólio, em relação aos da cultura in vitro dos embriões, utilizou-se o teste quiquadrado a $5 \%$ de probabilidade.

Outro experimento foi realizado com objetivo de avaliar o efeito da concentração da solução de tetrazólio e do tempo de coloração. Utilizaram-se três lotes de frutos, provenientes de três populações naturais de macaúba do Município de Montes Claros, com dois, cinco e oito meses de armazenamento, e determinou-se a umidade das sementes. Cinquenta embriões provenientes de cada um dos três lotes 
foram retirados e submetidos ao teste de tetrazólio, segundo a metodologia descrita anteriormente. Testaram-se dois tempos de coloração, duas e quatro horas, associados a três concentrações da solução de tetrazólio - 0,5, 0,75 e 1,0\% -, à temperatura de $35^{\circ} \mathrm{C}$ durante a coloração. $\mathrm{O}$ experimento foi realizado em delineamento inteiramente casualizado, em esquema fatorial constituido por 2 tempos de coloração e 3 concentrações da solução de tetrazólio, com cinco repetições de dez embriões. Em seguida, cinco repetições de dez embriões, de cada um dos lotes, foram cultivadas in vitro, conforme metodologia e critérios de avaliação descritos anteriormente. As avaliações e a análise estatística foram realizadas como no primeiro experimento. As análises foram feitas com o uso de programa do SAS Institute (1990).

\section{Resultados e Discussão}

O embrião da macaúba tem forma de clava, com duas regiões distintas: a proximal, localizada perifericamente em relação à semente (Figura $1 \mathrm{~A}$ ), que corresponde ao pecíolo cotiledonar; e a distal, em forma de bojo, que é o limbo cotiledonar ou haustório (Figura $1 \mathrm{~A}$ e B). O eixo embrionário está inserido em uma cavidade, no terço proximal do pecíolo cotiledonar, com alinhamento oblíquo em relação ao restante do embrião (Figura $1 \mathrm{C}$ e D). Os tecidos meristemáticos primários, protoderme, meristema fundamental e procâmbio são observados (Figura $1 \mathrm{E}$, F e G), em disposição característica. Alguns cordões procambiais partem do eixo embrionário e circundam a plúmula, enquanto outros cordões vascularizam a região distal do cotilédone, dispostos mais internamente, na região mediana do pecíolo (Figura $1 \mathrm{C}, \mathrm{D}$ e F), e perifericamente no haustório (Figura $1 \mathrm{C}, \mathrm{D}$ e $\mathrm{G}$ ). As células da protoderme formam invaginações evidentes no haustório (Figura $1 \mathrm{~B}, \mathrm{C}, \mathrm{D}$ e $\mathrm{G}$ ). A estrutura do embrião de macaúba acompanha o padrão geral, observado em outras palmeiras (Panza et al., 2004; Henderson, 2006), em que são peculiares a forma de bojo e as pronunciadas invaginações do haustório.

A localização interna do eixo embrionário dificulta a avaliação dos resultados do teste de tetrazólio. A secção do embrião para exposição do eixo embrionário e sua visualização em estereomicroscópio mostraram-se pouco práticas, pelas dificuldades para definição do plano de corte adequado. Assim, o padrão de avaliação foi elaborado a partir da divisão do embrião em três regiões: proximal do pecíolo, onde se localiza o eixo embrionário, mediana do pecíolo e haustório (Figura $1 \mathrm{D}$ ).

A ausência de considerações sobre a anatomia do embrião de palmeiras pode ocasionar numerosos erros na interpretação do teste de tetrazólio. As Regras para Análise de Sementes (Brasil, 1992) recomendam que, na avaliação do teste de tetrazólio em embriões de açaizeiro, seja considerada a coloração de estruturas meristemáticas da raiz e da parte aérea, sem o corte do embrião. No entanto, esta prática não é aplicável, uma vez que essas estruturas são internas e visíveis apenas a partir de secções anatômicas (Panza et al., 2004).

A observação dos embriões de macaúba submetidos à coloração permitiu a identificação de dez padrões principais de coloração, e a avaliação das plântulas produzidas pela germinação in vitro resultou na identificação de três estádios de desenvolvimento. A partir destas informações e da avaliação anatômica, propôs-se um esquema de avaliação com três classes de vigor (Tabela 1), conforme sugerido pela AOSA (Association of Official Seed Analysts, 2002, 2005; Marcos Filho, 2005). Em relação ao desenvolvimento da plântula, foram considerados: a) vigorosos aqueles embriões com capacidade de originar plântulas com raízes e bainhas foliares desenvolvidas (classe 1); b) embriões viáveis, aqueles com alto ou baixo vigor (classes 1 e 2), os quais mostraram capacidade de alongamento do eixo embrionário (Bewley \& Black, 1994) e originaram plântulas com raiz ou plântulas mais desenvolvidas; c) inviáveis, os embriões mortos ou incapazes de originar plântulas com raiz (classe3).

Pelos padrões de coloração, foram considerados vigorosos os embriões que apresentaram coloração uniforme (Tabela 1), com a ocorrência de áreas sem coloração, associadas à perda de vigor (Lakon, 1949; Brasil, 1992; França Neto et al., 2000; Association of Official Seed Analysts, 2002, 2005). Para determinar a viabilidade do embrião, considerou-se essencial a coloração da região proximal do pecíolo, em razão da localização do eixo embrionário. Admitiram-se como viáveis os embriões com áreas sem coloração, desde que restritas à região mediana do pecíolo e ao haustório, conforme critérios de avaliação relatados na literatura quanto a outras espécies. Estas considerações basearam-se no fato de que, nestas regiões, os cordões procambiais apresentam distribuição mais ampla (Figura $1 \mathrm{~F}$ e $\mathrm{G}$ ) do que na proximal, de modo que os 

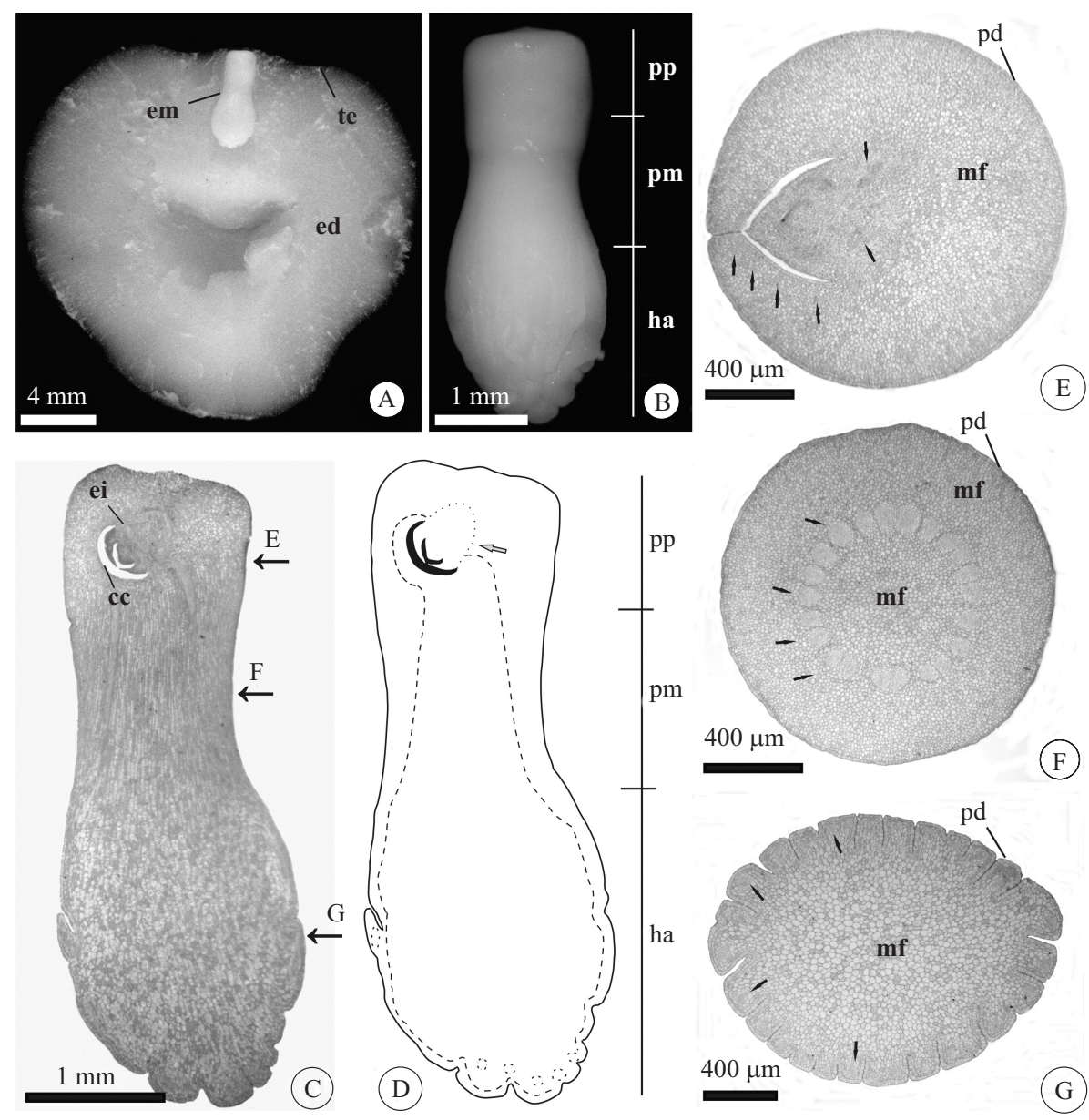

Figura 1. Estrutura do embrião de macaúba: Embrião inserido na semente (A); Regiões morfológicas do embrião (B); Secção longitudinal do embrião, destacandose a cavidade cotiledonar, o eixo embrionário e as alturas aproximadas das secções transversais E, F e G, indicadas pelas setas (C); Secção longitudinal, com evidência das regiões do embrião, especialmente o eixo embrionário (seta) e distribuição dos cordões procambiais (em tracejado) (D); Secções transversais da região proximal do pecíolo (E), região mediana do pecíolo (F) e haustório (G), em que se destaca a posição dos cordões procambiais (setas). Na estrutura destacam-se: cc, cavidade cotiledonar; ed, endosperma; ei, eixo embrionário; em, embrião; ha, haustório; mf, meristema fundamental; pd, protoderme; pp, região proximal do pecíolo; pm, região mediana do pecíolo; te, tegumento.

possíveis danos localizados, que poderiam prejudicar a translocação de substâncias, podem ser compensados, ao menos parcialmente, pelos feixes vasculares que serão diferenciados pelos outros cordões. Do mesmo modo, os efeitos de danos localizados na região periférica do haustório, que tem a função de absorver reservas do endosperma (Panza et al., 2004; Henderson, 2006), podem ser compensados pela atividade de outras regiões da mesma estrutura. Quanto às sementes de vários gêneros de Poaceae, a Association of Official Seed Analysts (2002) admitiu como viáveis embriões com até um terço da folha cotiledonar sem coloração. Spera et al. (2001) analisaram o buriti e consideraram viáveis os embriões que apresentaram até a metade do haustório sem coloração, enquanto as Regras para Análise de Sementes (Brasil, 1992) admitem como viáveis os embriões de açaizeiro com cotilédones parcialmente descoloridos. 
Observou-se que $71 \%$ dos embriões de macaúba estavam parcial ou totalmente corados de rosa. Wood et al. (2005) afirmaram que a predominância da coloração rosada no teste de tetrazólio é comum em espécies oleaginosas, em razão das dificuldades para a difusão da solução ou para o estabelecimento da coloração, o que foi também observado em sementes oleaginosas de outros grupos, como a castanheira-do-pará, Bertholletia excelsa Humb. \& Bompl. (Camargo et al., 1997). Lin (1988) trabalhou com o açaizeiro e considerou inviáveis embriões corados de rosa, o que não se mostrou apropriado para explicar os resultados dos testes de germinação.

Os resultados do teste de tetrazólio e da cultura de embriões e o pré-condicionamento por imersão em água e a temperatura de incubação não apresentaram diferenças estatísticas (Tabela 2) quantoà viabilidade ou vigor, o que indica que o esquema de avaliação mostrou-se adequado. De acordo com as Regras para Análise de Sementes (Brasil, 1992), tanto o teste de tetrazólio quanto o padrão de desenvolvimento de embriões isolados podem ser utilizados como indicadores de viabilidade. No entanto, trabalhos com diferentes espécies demonstraram a existência de correlação significativa entre os resultados do teste de tetrazólio e de testes de germinação e vigor (Spera et al., 2001; Barros et al., 2005; Bhering et al., 2005; Fogaça et al., 2006; Oliveira et al., 2006). No presente trabalho, não houve efeito dos tratamentos de pré-condicionamento e temperatura de incubação sobre a coloração obtida com tetrazólio. Costa \& Marcos Filho (1994) afirmaram que a embebição prévia das sementes de soja pode favorecer a ativação enzimática e a penetração do tetrazólio. No presente trabalho, a exposição direta dos embriões à solução foi suficiente para realização do teste sem pré-condicionamento, o que também ocorre com o açaizeiro (Brasil, 1992). Embora Marcos Filho (2005) e Wood et al. (2005) tenham sugerido que temperaturas de incubação mais altas podem favorecer a coloração de sementes oleaginosas, isto não foi observado nos embriões de macaúba.

Os experimentos sobre a concentração da solução de tetrazólio e o tempo de coloração evidenciaram efeitos dos tratamentos apenas no percentual de embriões vigorosos, no lote com teor de umidade de $7,9 \%$ (Tabela 3 ). Neste lote, o tempo de duas horas foi suficiente para o desenvolvimento de coloração que permitiu a identificação dos embriões viáveis, mas insuficiente para permitir a distinção entre

Tabela 1. Padrões de coloração de embriões de macaúba, observados no teste de tetrazólio, e classes de vigor correspondentes associadas ao grau de desenvolvimento de plântulas de macaúba, cultivadas in vitro.

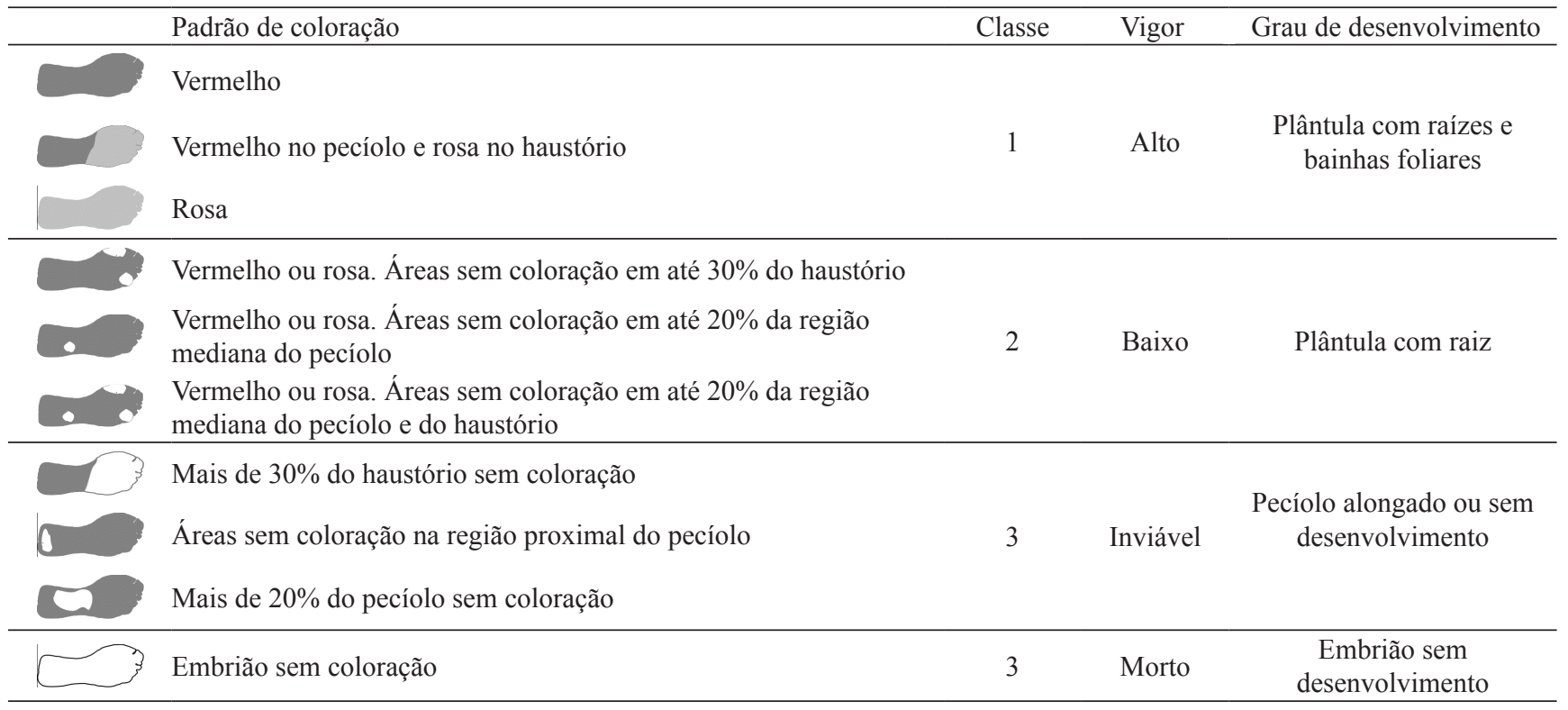


Tabela 2. Percentuais médios de embriões de macaúba viáveis e vigorosos, determinados pelo teste de tetrazólio, em diferentes tempos de pré-condiconamento e temperaturas de coloração, e pela cultura in vitro dos embriões, em lotes de sementes com diferentes teores de água ${ }^{(1)}$.

\begin{tabular}{|c|c|c|c|c|c|}
\hline \multirow{2}{*}{ Tempo (h) } & \multirow{2}{*}{ Temperatura $\left({ }^{\circ} \mathrm{C}\right)$} & \multicolumn{2}{|c|}{$8,9 \%$} & \multicolumn{2}{|c|}{$11,2 \%$} \\
\hline & & Viáveis & Vigorosos & Viáveis & Vigorosos \\
\hline & & \multicolumn{4}{|c|}{ Teste de tetrazólio } \\
\hline 0 & 35 & 82 & 58 & 90 & 80 \\
\hline 12 & 35 & 86 & 62 & 92 & 80 \\
\hline 24 & 35 & 86 & 58 & 86 & 74 \\
\hline 0 & 40 & 78 & 58 & 92 & 78 \\
\hline 12 & 40 & 82 & 54 & 90 & 76 \\
\hline \multirow[t]{2}{*}{24} & 40 & 84 & 60 & 90 & 74 \\
\hline & & \multicolumn{4}{|c|}{ Cultura de embriões } \\
\hline
\end{tabular}

(1)Não foram constatadas diferenças significativas entre os tratamentos referentes ao teste de tetrazólio ao nível de 5\% de probabilidade, pelo teste de Tukey. Não foram observadas diferenças significativas entre os resultados de cada tratamento do teste de tetrazólio em relação aos resultados da cultura de embrião pelo teste Qui-quadrado ao nível de 5\% de probabilidade. as classes de alto e baixo vigor, o que ocasionou resultados discrepantes em relação à cultura in vitro dos embriões. Este resultado não foi observado nos outros lotes, possivelmente em razão da maior facilidade de coloração associada à maior atividade metabólica dos embriões. Todas as concentrações mostraram-se adequadas, quando a coloração foi realizada por quatro horas; não foi observada divergência estatística em relação aos resultados da cultura de embrião ou entre os tratamentos entre si. Estes resultados estão condizentes com outros trabalhos sobre embriões de palmeiras (Ferreira \& Sader, 1987; Fernandes et al., 2007; Spera et al., 2001). Considerando-se haver interesse na economia da solução, os dados aqui obtidos indicam que a concentração de $0,5 \%$ de sal de tetrazólio, por período de quatro horas de coloração para embriões de macaúba, sem necessidade de tratamentos prévios, é adequada.

Tabela 3. Percentuais médios de embriões de macaúba viáveis e vigorosos, determinados pelo teste de tetrazólio em diferentes concentrações e tempos de coloração, e pela cultura in vitro de embriões, em lotes de sementes com diferentes teores de água ${ }^{(1)}$.

\begin{tabular}{|c|c|c|c|c|c|c|c|}
\hline \multirow{2}{*}{ Tempo (h) } & \multirow{2}{*}{ Concentração (\%) } & \multicolumn{2}{|c|}{$7,9 \%$} & \multicolumn{2}{|c|}{$11,0 \%$} & \multicolumn{2}{|c|}{$20,4 \%$} \\
\hline & & Viáveis & Vigorosos & Viáveis & Vigorosos & Viáveis & Vigorosos \\
\hline & & \multicolumn{6}{|c|}{ Teste de tetrazólio } \\
\hline 2 & 0,50 & 58 & $12 \mathrm{bB}$ & 82 & 62 & 94 & 84 \\
\hline 2 & 0,75 & 66 & $16 \mathrm{bB}$ & 80 & 62 & 96 & 86 \\
\hline 2 & 1,00 & 66 & $18 \mathrm{bB}$ & 84 & 66 & 100 & 84 \\
\hline 4 & 0,50 & 70 & $38 \mathrm{aA}$ & 88 & 72 & 100 & 86 \\
\hline 4 & 0,75 & 72 & $40 \mathrm{aA}$ & 86 & 70 & 98 & 88 \\
\hline 4 & 1,00 & 68 & $40 \mathrm{aA}$ & 86 & 74 & 96 & 90 \\
\hline
\end{tabular}

Cultura de embriões

$\begin{array}{llllll}68 & 38 \mathrm{~A} & 80 & 68 & 96 & 82\end{array}$

(1)Médias seguidas de letras minúsculas diferentes, entre os tratamentos do teste de tetrazólio, diferem entre si pelo teste de Tukey, a 5\% de probabilidade. Médias seguidas de letras maiúsculas diferentes do tratamento do teste de tetrazólio, em relação às da cultura in vitro dos embriões, diferem entre si, pelo teste qui-quadrado a $5 \%$ de probabilidade.

\section{Conclusões}

1. O esquema de avaliação proposto para o teste de tetrazólio, com dez padrões de coloração e três classes de vigor, é adequado para a avaliação de embriões de macaúba.

2. O teste de tetrazólio pode ser aplicado em embriões de macaúba, sem pré-condicionamento por imersão em água, pelo período de coloração de quatro horas, em solução de 2,3,5-trifenil cloreto de tetrazólio a $0,5 \%$ e a $35^{\circ} \mathrm{C}$.

\section{Agradecimentos}

À Fundação de Amparo a Pesquisa do Estado de Minas Gerais e ao Conselho Nacional de 
Desenvolvimento Científico e Tecnológico, pela bolsa de estudos, ao nível de Doutorado, concedida ao primeiro autor.

\section{Referências}

ASSOCIATION OF OFFICIAL SEED ANALYSTS. Tetrazolium testing handbook: contribution $\mathrm{n}^{\circ} 29$ to the Seed vigor testing handbook: 2002 update. Ithaca: AOSA, 2002. 26p.

ASSOCIATION OF OFFICIAL SEED ANALYSTS. Tetrazolium testing handbook: contribution $\mathrm{n}^{\circ} 29$ to the Seed vigor testing handbook: 2005 update. Ithaca: AOSA, 2005. 32p.

BANDEIRA, F.S. Cultivo in vitro e embriogênese somática de embriões zigóticos de macaúba Acrocomia aculeata (Jacq.) Loddiges. 2008. 92p. Tese (Doutorado) - Universidade Federal de Viçosa, Viçosa.

BARROS, D.I.; DIAS, D.C.F. dos S.; BHERING, M.C.; DIAS, L.A. dos S.; ARAÚJO, E.F. Uso do teste de tetrazólio para avaliação da qualidade fisiológica de sementes de abobrinha. Revista Brasileira de Sementes, v.27, p.165-171, 2005.

BEWLEY, J.D.; BLACK, M. Seeds: physiology of development and germination. New York: Plenum Press, 1994. 445p.

BHERING, M.C.; DIAS, D.C.F. dos S.; BARROS D.I. Adequação da metodologia do teste de tetrazólio para avaliação da qualidade fisiológica de sementes de melancia. Revista Brasileira de Sementes, v.27, p.176-182, 2005.

BRASIL. Ministério da Agricultura e Reforma Agrária. Secretaria Nacional de Defesa Agropecuária. Regras para análise de sementes. Brasília: SNDA, 1992. 365p.

CAMARGO I.P. de; CARVALHO, M.L.M. de; VIEIRA, M. das G.G.C. Avaliação da deterioração em sementes de castanheira-dobrasil pelo teste de tetrazólio. Pesquisa Agropecuária Brasileira, v.32, p.835-839, 1997.

COSTA, N.P. da; MARCOS FILHO, J. Temperatura e précondicionamento de sementes de soja para o teste de tetrazólio. Scientia Agrícola, v.51, p.158-168, 1994.

FERNANDES, R.C.; MAGALHÃES, H.M.; LOPES, P.S.N.; BRANDÃO JÚNIOR, D.S.; FERNANDES, R.C.; GOMES, J.A.O.; PAULINO, M.A.O.; CARNEIRO, P.A.P. Elaboração da metodologia de aplicação do teste de tetrazólio para avaliação da viabilidade das sementes de coquinho-azedo Butia capitata (Mart)

Becc. Revista Brasileira de Agroecologia, v.2, p.1004-1007, 2007. FERREIRA, S.A.N.; SADER, R. Avaliação da viabilidade de sementes de pupunha (Bactris gasipaes H.B.K.) pelo teste de tetrazólio. Revista Brasileira de Sementes, v.9, p.109-114, 1987.

FOGAÇA, C.A.; MALAVASI, M. de M.; ZUCARELI, C.; MALAVASI, U.C. Aplicação do teste de tetrazólio em sementes de
Gleditschia amorphoides Taub. Caesalpinaceae. Revista Brasileira de Sementes, v.28, p.101-107, 2006.

FRANÇANETO, J. de B.; PEREIRA, L.A.G.; KRZYZANOWSKI, F.C.; COSTA, N.P. da. Metodologia do teste de tetrazólio em sementes de soja. Londrina: Embrapa-CNPSo, 2000. 72p.

HENDERSON, F.M. Morphology and anatomy of palm seedlings. The Botanical Review, v.72, p.273-329, 2006.

HIANE, P.A.; RAMOS FILHO, M.M.; RAMOS, M.I.L.; MACEDO, M.L.R. Bocaiúva, Acrocomia aculeata (Jacq.) Lodd., pulp and kernel oils: characterization and fatty acid composition. Brazilian Journal of Food Technology, v.8, p.256-259, 2005.

JOHANSEN, D.A. Plant microtechnique. New York: McGrawHill, 1940. 523p.

LAKON, G. The topographical tetrazolium method for determining the germinating capacity of seeds. Plant Physiology, v.24, p.389394, 1949.

LIN, S.S. Efeito do tamanho e maturidade sobre a viabilidade, germinação e vigor do fruto de palmiteiro. Revista Brasileira de Sementes, v.8, p.57-66, 1988.

MARCOS FILHO, J. Fisiologia de sementes de plantas cultivadas. Piracicaba: Fealq, 2005. 495p.

O'BRIEN, T.P.; FEDER, N.; MCCULLY, M.E. Polychromatic staining of plant cell walls by toluidine blue O. Protoplasma, v.59, p.368-373, 1964.

OLIVEIRA, A.K.M. de; SCHLEDER, E.D.; FAVERO, S. Caracterização morfológica, viabilidade e vigor de sementes de Tabebuia aurea (Silva Manso) Benth. \& Hook. f. ex. S. Moore. Revista Árvore, v.30, p.25-32, 2006.

OROZCO-SEGOVIA, A.; BATIS, A.I.; ROJA-ARÉCHIGA, M; MENDOZA, A. Seed biology of palms: a review. Palms, v.47, p.79-94, 2003.

PANZA V.; LÁINEZ, V.; MALDONADO, S. Seed structure and histochemistry in the palm. Euterpe edulis. Botanical Journal of the Linnean Society, v.145, p.445-453, 2004.

SAS INSTITUTE. SAS user's guide: statistics version. Cary: SAS Institute, 1990. 846p.

SPERA, M.R.N.; CUNHA, R. da; TEIXEIRA, J.B. Quebra de dormência, viabilidade e conservação de sementes de buriti (Mauritia flexuosa). Pesquisa Agropecuária Brasileira, v.36, p.1567-1572, 2001.

TEIXEIRA, L.C. Potencialidades de oleaginosas para produção de biodiesel. Informe Agropecuário, v.26, p.18-27, 2005.

WOOD, C.B.; MILES, S.; RIX, C.; TERRY, J.; DAWS, M.I. The effect of seed oil content on viability assessment using tetrazolium: a case study using 171 species. Plant Genetic Resources Newsletter, v.143, p.17-23, 2005.

Recebido em 2 de março de 2010 e aprovado em 30 de março de 2010

Pesq. agropec. bras., Brasília, v.45, n.4, p.361-368, abr. 2010 